ISSN: 1679-3013

D.O.I.: 10.5914/1679-3013.2014.0098

\title{
AVALIAÇÃO DAS CONDIÇÕES AMBIENTAIS DO ESTUÁRIO DO RIO CARRAPICHO (Itamaracá-PE): BIOMASSA FITOPLANCTÔNICA E HIDROLOGIA.
}

\begin{tabular}{|c|c|}
\hline & $\begin{array}{l}\text { Natali Ferreira, CASTRO }{ }^{1} \\
\text { Fernando Antônio do N. FEITOSA }{ }^{2} \\
\text { Manuel de Jesus, FLORES MONTES } 2\end{array}$ \\
\hline Recebido em: $16 / 03 / 2013$ & \\
\hline Aceito em: $23 / 07 / 2014$ & \\
\hline \multicolumn{2}{|c|}{ ABSTRACT } \\
\hline $\begin{array}{l}\text { The present study aims to evaluate the } \\
\text { environmental conditions of the Carrapicho } \\
\text { River estuary (Itamaracá, } \mathrm{PE} \text {, Brazil). Water } \\
\text { samples were collected at three stations, } \\
\text { monthly, from March/07 to February/08, } \\
\text { using Niskin bottles on the surface at } \\
\text { daytime low and high tide. The annual } \\
\text { rainfall during the sampling period ranged } \\
\text { from } 25.6 \text { to } 390.8 \mathrm{~mm} \text {; depth ranged from } \\
2.6 \text { to } 25 \mathrm{~m} \text {; temperature ranged from } 26 \text { to } \\
31^{\circ} \mathrm{C} \text {; transparency ranged from } 1.0 \text { to } 3.5 \\
\mathrm{~m} \text {; salinity ranged from } 20.2 \text { to } 38.2 \text {; } \\
\text { dissolved oxygen ranged from } 2.2 \text { to } 6.2 \\
\mathrm{ml} / \mathrm{L} \text {; percentage of oxygen saturation }\end{array}$ & $\begin{array}{l}\text { ranged from } 48.4 \text { to } 105.5 \% \text {; } \mathrm{pH} \text { ranged } \\
\text { from } 7.8 \text { to } 8.8 \text {; ammonia ranged from } 0.01 \\
\text { to } 0.16 \mu \mathrm{mol} / \mathrm{L} \text {; nitrite ranged from } 0.01 \text { to } \\
0.22 \mu \mathrm{mol} / \mathrm{L} \text {; nitrate ranged from } 0.06 \text { to } 12 \\
04 \mu \mathrm{mol} / \mathrm{L} \text {; phosphate ranged from } 0.01 \text { to } \\
1.9 \mu \mathrm{mol} / \mathrm{L} ; \text { silicate ranged from } 1.3 \mu \mathrm{mol} / \mathrm{L} \\
\text { to } 47 \mu \mathrm{mol} / \mathrm{L} \text {; suspended particulate matter } \\
\text { ranged from } 3 \text { to } 63 \mathrm{mg} / \mathrm{L} \text {; A Chlorophyll } \\
\text { ranged from } 2.3 \text { to } 40 \mathrm{mg} \cdot \mathrm{m}^{-3} \text {. Carrapicho } \\
\text { River was characterized as coastal plain, low } \\
\text { sediment transport capacity. Its salinity } \\
\text { regime varies from polyhaline to euhaline } \\
\text { and still exempt from the process of } \\
\text { eutrophication. }\end{array}$ \\
\hline
\end{tabular}

Key words: estuarine zone, chlorophyll a, environmental variables.

\section{RESUMO}

O presente trabalho teve como objetivo principal avaliar as condições ambientais do estuário do rio Carrapicho (ItamaracáPernambuco-Brasil). As amostras de água foram coletadas em três estações, mensalmente, no período de março/07 a fevereiro/08, com garrafas de Niskin, na superfície, em baixa-mar e preamar diurnas. A pluviosidade anual durante o período amostrado variou de 25,6a 390,8mm; a profundidade de 2,6 a $25 \mathrm{~m}$; a temperatura variou de 26 a $31^{\circ} \mathrm{C}$; a transparência de 1,0 a $3,5 \mathrm{~m}$; a salinidade de 20,2 a 38,$2 ; 0$ oxigênio dissolvido de 2,2 a $6,2 \mathrm{ml} / \mathrm{L} ; 0$ percentual de saturação do oxigênio de 48,4 a $105,5 \%$; $\mathrm{pH}$ variou de 7,8 a 8,8 ; a amônia de 0,01 a 0,16 $\mu \mathrm{mol} / \mathrm{L} ; 0$ nitrito de 0,01 a $0,22 \mu \mathrm{mol} / \mathrm{L} ; \quad 0$ nitrato de 0,06 a 12,04 $\mu \mathrm{mol} / \mathrm{L} ;$ o fosfato de 0,01 a $1,9 \mu \mathrm{mol} / \mathrm{L} ; 0$ silicato 1,3 a $47 \mu \mathrm{mol} / \mathrm{L} ; \quad 0$ material particulado em suspensão de 3 a $63 \mathrm{mg} / \mathrm{L}$; Clorofila a de 2,3 a $40 \mathrm{mg} \cdot \mathrm{m}^{-3}$. O rio Carrapicho caracterizou-se como sendo do tipo litorâneo de planície, de baixa capacidade de transporte de sedimento, com regime de salinidade variando de polihalino a euhalino e ainda isento do processo de eutrofização.

Palavras chave: zona estuarina, clorofila a, variáveis ambientais.

\section{INTRODUÇÃo}

Os ambientes estuarinos são regiões costeiras semi-fechadas nas desembocaduras dos rios, sujeitas aos aportes dos rios e do fluxo marinho. Os nutrientes transportados pelos rios e a rápida troca entre as águas de superfície e sedimentos contribuem para uma produtividade biológica extremamente alta, sendo considerado um dos ecossistemas mais produtivos da Terra. Essa alta produtividade resulta da regeneração rápida e local dos nutrientes bem como dos aportes destes pelos rios e marés. Sua importância se estende aos ecossistemas marinhos através da sua exportação líquida de matéria orgânica, organismos e detritos particulados e dissolvidos (RICKLEFS, 2003). 
CASTRO, N. F.; FEITOSA, F. A. do N.; FLORES MONTES, M. de J. Avaliação das condições Ambientais do estuário do rio Carrapicho (Itamaracá- PE): Biomassa fitoplanctônica e Hidrologia.

De acordo com Mateus et al. (2008), estuários são ambientes altamente dinâmicos na sua estrutura física, química e biológica, caracterizados pela variabilidade temporal e espacial. Estão sujeitos a contínuas variações nos ventos, irradiância, pluviosidade, nível da correnteza de água doce. Portanto, pode-se dizer que é um sistema de transição governado por um complexo de elementos, interagindo, os quais variam no tempo e no espaço.

Devido à sua alta produtividade e ao abrigo que oferecem aos organismos, os estuários com seus manguezais são áreas de alimentação importantes, sustentando populações abundantes de espécies estuarinas e marinhas, como as diversas fases iniciais do ciclo de vida de muitos peixes e invertebrados, que completam seu ciclo de vida no mar (SILVA, 2002).

No litoral norte de Pernambuco, destaca-se o complexo estuarino de Itamaracá, localizado

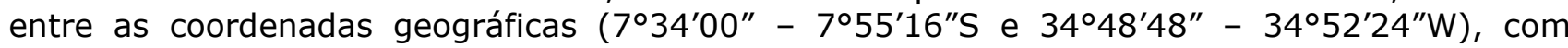
vastas áreas de manguezais associadas ao canal de Santa Cruz e aos estuários de vários rios que nele desembocam (LIRA, 1975). Foi considerado como APA (Área de Proteção Ambiental) pelo decreto de n. 32.488 de 17 de outubro de 2008.

Nos ecossistemas estuarinos, o fitoplâncton é muito mais abundante que nas áreas costeiras e oceânicas, exatamente pelo fato de nos estuários o suprimento de nutrientes ser maior, em virtude da drenagem constante das águas dos rios e ciclagem dos resíduos orgânicos decorrente da decomposição da matéria orgânica (TUNDISI, 1970).

Conforme Eskinazi-Leça et al. (2000) as algas planctônicas tem grande significado ecológico e sua importância reside não só no fato de constituírem o início da teia alimentar, como também é a principal fornecedora de oxigênio atmosférico do planeta e ainda sustentam uma grande diversidade de espécies ao longo da teia trófica. Devido ao fato delas responderem rapidamente aos impactos ambientais, torna-se, assim, ótimas indicadoras da qualidade ambiental e de massas d'águas. A análise da estrutura da comunidade fitoplanctônica é relevante para se conhecer a composição, biomassa, densidade e produtividade do ecossistema aquático, além de diagnosticá-lo, uma vez que algumas espécies são bioindicadoras da qualidade ambiental (BRANCO, 2006). Baseando nisto, o presente trabalho teve como objetivo principal avaliar o estuário do rio Carrapicho através da medida de biomassa fitoplanctônica (clorofila a), parâmetros hidrológicos e dinâmica estuarina.

\section{DESCRIÇÃO DA ÁREA}

O rio Carrapicho está situado no litoral norte do Canal de Santa Cruz (ItamaracáPernambuco), pertence à bacia do rio Itapessoca, que está localizado na porção sul - oriental do município de Goiana. Com uma área total de 12.584,06 ha, o que representa 9,2\% da superfície do litoral norte e $25,3 \%$ do município de Goiana. Limita-se, ao norte, com a bacia do rio Goiana; ao sul, com a bacia dos rios Botafogo-Arataca e com o Canal de Santa Cruz; a oeste, com a sub-bacia do Botafogo; e, a leste, com as micro bacias da vertente atlântica. Possui aproximadamente $10 \mathrm{~km}$ de extensão, sendo considerado um dos principais tributário do complexo estuarino do canal de Santa Cruz (CPRH, 2013).

Sua profundidade média é de $6 \mathrm{~m}$ e possui as margens formadas por denso manguezal, típico de regiões tropicais ribeirinhas, representado pelas seguintes espécies Rhizophora mangle, Laguncularia racemosa, Avicennia germinans, Avicennia schaueriana e Conocarpus erectus. O rio Carrapicho é um rio litorâneo que nasce nas proximidades do município de Tejucupapo e corre na direção sul, banhando a ilha de Itapessoca e desaguando no canal de Santa Cruz na altura da Barra de Catuama. Ele apresenta na sua margem esquerda um único rio tributário que é o rio Siri ou Sirigi. É considerado um porto natural por apresentar em alguns pontos $25 \mathrm{~m}$ de profundidade ( $\mathrm{CPRH}, 2013)$.

De acordo com Köeppen ele está inserido numa região cujo clima é do tipo As `com dois períodos distintos, onde o chuvoso ocorre de março a agosto e o de estiagem de setembro a fevereiro. O índice de chuva é de $2000 \mathrm{~mm}$ anuais, a temperatura do ar média é em torno de $27^{\circ} \mathrm{C}$ (TORRES; MACHADO, 2011). As atividades predominantes na bacia são as culturas da cana-de-açúcar, do coco e de outras frutarias, a avicultura, fazendas de camarão (Netuno e outras empresas), a exploração de areia no baixo vale do rio Siri, bem como a extração de 
CASTRO, N. F.; FEITOSA, F. A. do N.; FLORES MONTES, M. de J. Avaliação das condições Ambientais do estuário do rio Carrapicho (Itamaracá- PE): Biomassa fitoplanctônica e Hidrologia.

calcário para a produção de cimento (da empresa Nassau do grupo João Santos, localizada no interior da ilha de Itapessoca) e de cal (no Engenho Megaó de cima, em Tejucupapo).

\section{MATERIAL E MÉTODOS}

As coletas foram realizadas, mensalmente, de março de 2007 a fevereiro de 2008, em três estações de coletas fixas no estuário do rio Carrapicho, na superfície, nos estágios de baixa-mar e preamar diurna (Figura 1). As amostras foram obtidas através de garrafa oceanográfica de Niskin e depois acondicionadas em locais adequados. Os parâmetros analisados foram: pluviosidade, através da estação INMET (Instituto Nacional de Meteorologia), localizada no Curado; profundidade local, através de uma ecossonda da Echotest; temperatura, através de termômetro comum com escala entre -10 e $60^{\circ} \mathrm{C}$; transparência da água, por intermédio de um disco de Secchi; salinidade, através do método de titulação de MhorKnudsen; oxigênio dissolvido (OD), pelo método de Winkler modificado e descrito por Strickland e Parsons (1972); percentual de saturação de oxigênio, utilizando a tabela da UNESCO (1973); $\mathrm{pH}$, através de um potenciômetro da Hanna Instruments; os nutrientes dissolvidos nitrito, nitrato, fosfato pelo método de Strickland e Parsons (1972), amônia e o silicato por Grasshoff et al. (1983); material particulado em suspensão pelo método de Baumgarten (1996); biomassa fitoplanctônica (clorofila a), pelo método espectrofotométrico da UNESCO (1966), e para o cálculo usou-se a fórmula de Parsons e Strickland (1963); para análise estatística dos dados foi utilizado PERMANOVA (Permutational Multivariate Analysis of Variance), onde três fatores foram aplicados. O fator 1 'estações de coleta' possui três níveis (estações 1,2 e 3) o fator 2 'sazonalidade' possui dois níveis (chuvoso e estiagem), e o fator 3 'maré' possui dois níveis (baixa-mar e preamar).

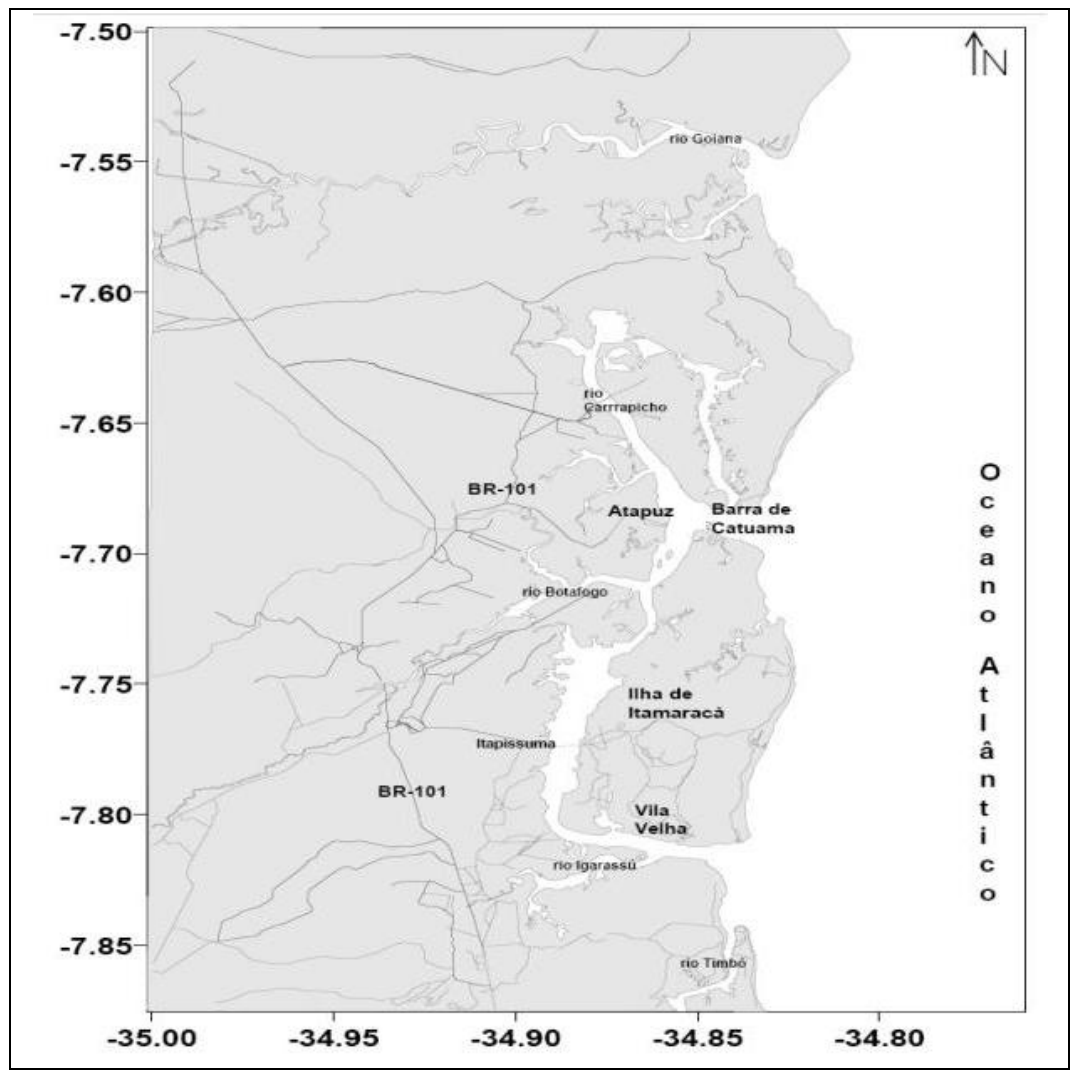

Figura 1 - Mapa da área estudada, com indicativo das estações de coleta no estuário do rio Carrapicho.

\section{Precipitação Pluviométrica}

RESULTADOS

A pluviosidade durante o período estudado acompanhou a curva da média de dezessetes anos (1992 a 2008). O valor máximo da precipitação pluviométrica foi de $390,8 \mathrm{~mm}$ em junho/07, e o mínimo de 25,6 mm em outubro/07 (Figura 2). A mediana no período chuvoso foi de $217,5 \mathrm{~mm}$, e no período estiagem foi de $83,5 \mathrm{~mm}$ (Tabela 1 ). 


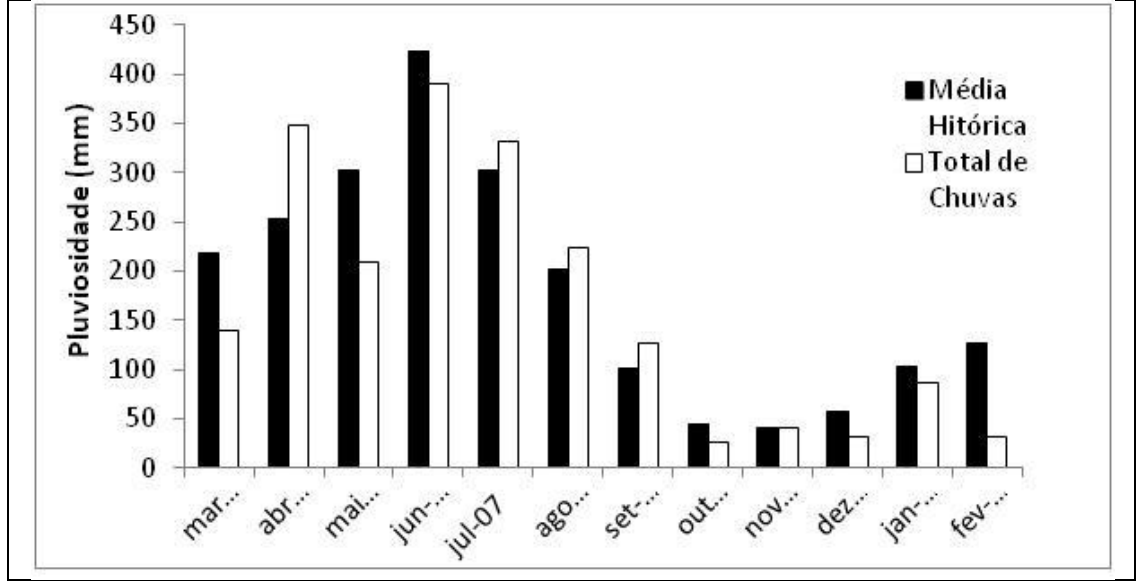

Figura 2 - Variação anual da precipitação pluviométrica na área estudada comparada com a média de dezessete anos (1992 a 2008).

\section{Profundidade}

O ambiente estudado, de forma geral, foi considerado raso, com profundidade mínima de 2,6m na estação 1, em abril/2007, agosto/07 e janeiro/08, durante a vaıxa-mar, e a máxima de $25 \mathrm{~m}$ na estação 3, em dezembro/07, durante a preamar (Figura 3). A profundidade no período chuvoso apresentou um valor para mediana de 5,4 m, e estiagem de 7,1m (Tabela 1).

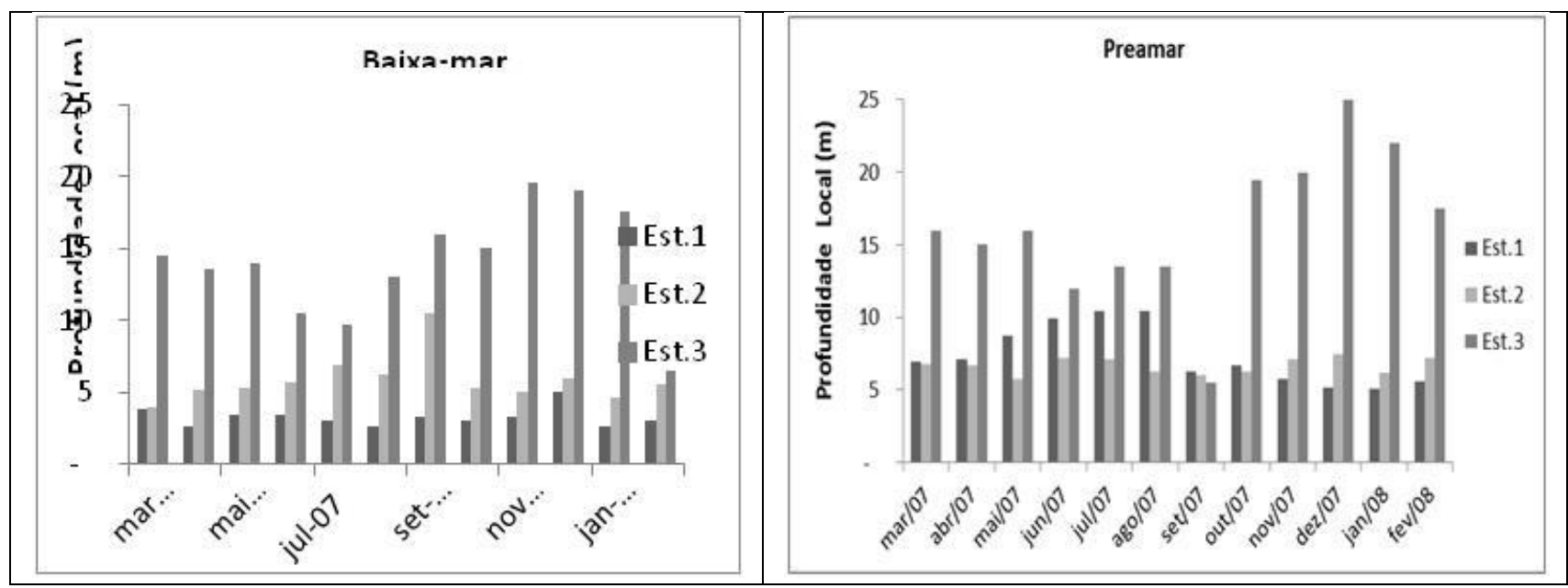

Figura 3 - Variação anual da profundidade local nas estações de coleta 1, 2 e 3 no estuário do rio Carrapicho.

\section{Temperatura}

Em relação à temperatura da água foi observada uma amplitude térmica de apenas $5^{\circ} \mathrm{C}$, sendo o menor valor de $26^{\circ} \mathrm{C}$ na estação 1 , em outubro/07, na preamar, e o valor maior de $31^{\circ} \mathrm{C}$, nas estações 1, 2 e 3, em fevereiro/08, na preamar (Figura 4). A mediana para o período chuvoso foi $29,3^{\circ} \mathrm{C}$, e estiagem $29,5^{\circ} \mathrm{C}$ (Tabela 1 ). 


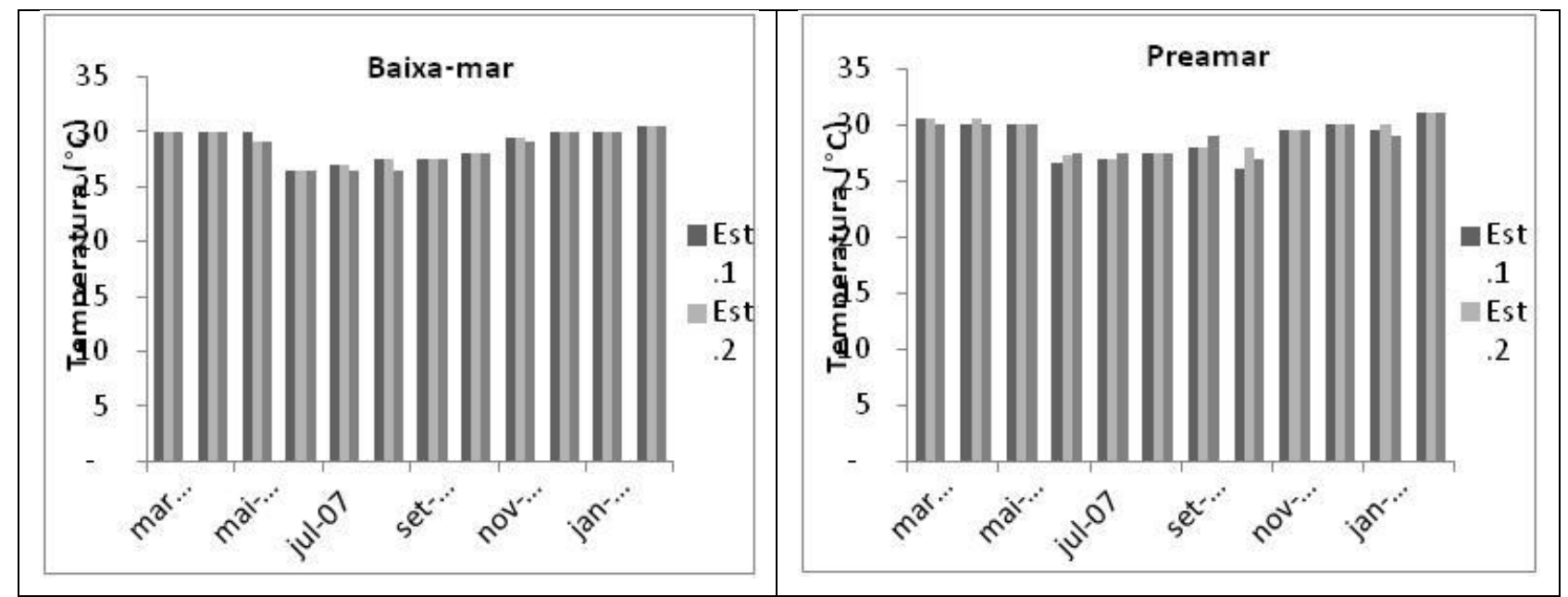

Figura 4 - Variação anual da temperatura nas estações de coleta 1, 2 e 3 no estuário do rio Carrapicho.

\section{Transparência}

O valor mínimo para transparência da água foi de $1,0 \mathrm{~m}$ registrado no ponto 2 , em junho/07 e na estação 1 em outubro/07, ambos durante a preamar, e o máximo de 3,5m na estação 3, em fevereiro/08, na preamar (Figura 5). A mediana no período chuvoso foi $2 \mathrm{~m}$, estiagem foi $1,5 \mathrm{~m}$ (Tabela 1 ).

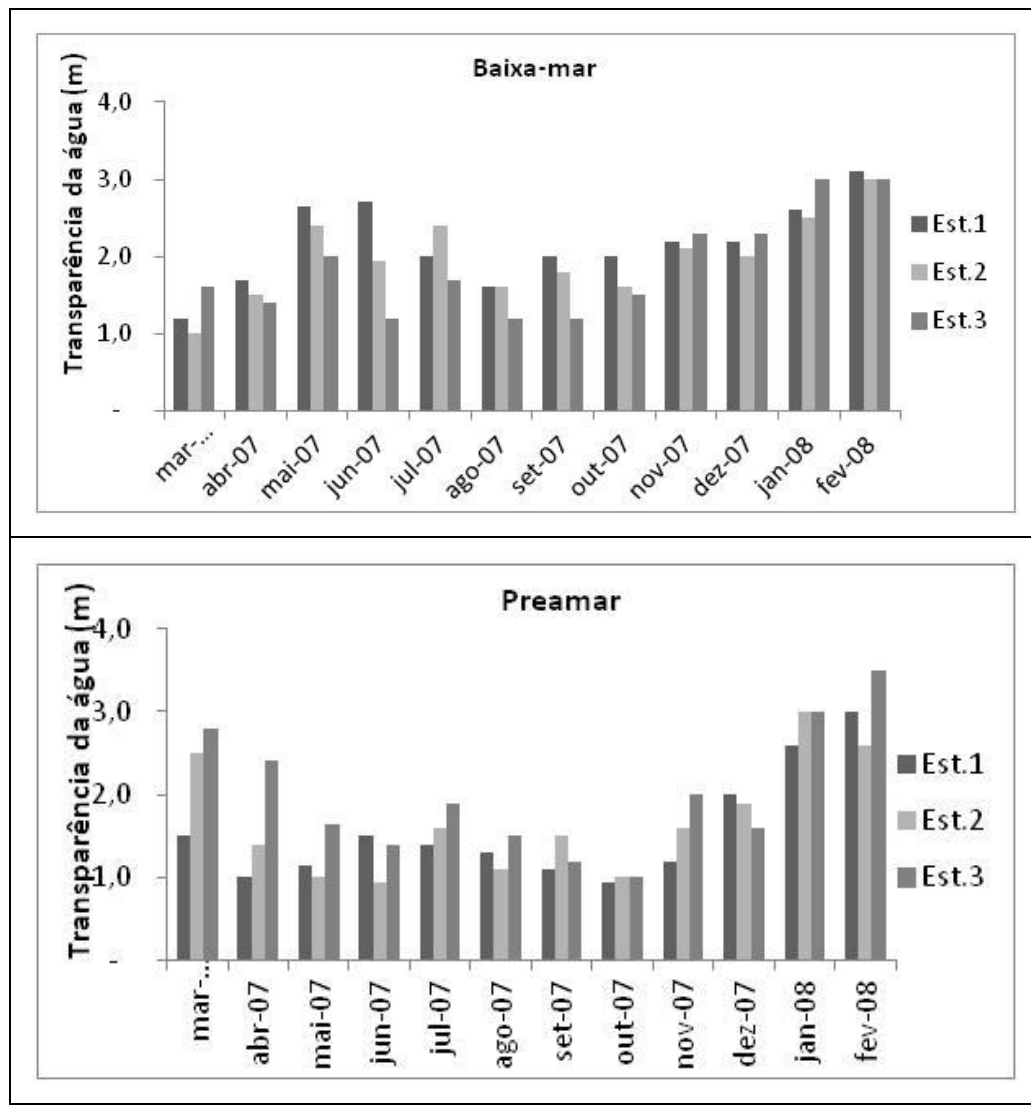

Figura 5 - Variação anual da transparência da água nas estações de coleta 1,2 e 3 no estuário do rio Carrapicho

\section{Salinidade}

O valor mínimo para salinidade foi de 20,2 na estação 2, em junho/07, período chuvoso, na baixa-mar; enquanto que o máximo foi de 38,2 na estação 2, em fevereiro/08, na preamar (Figura 6). A mediana para salinidade no período chuvoso foi 31,7 , e estiagem foi 34 (Tabela 1). 


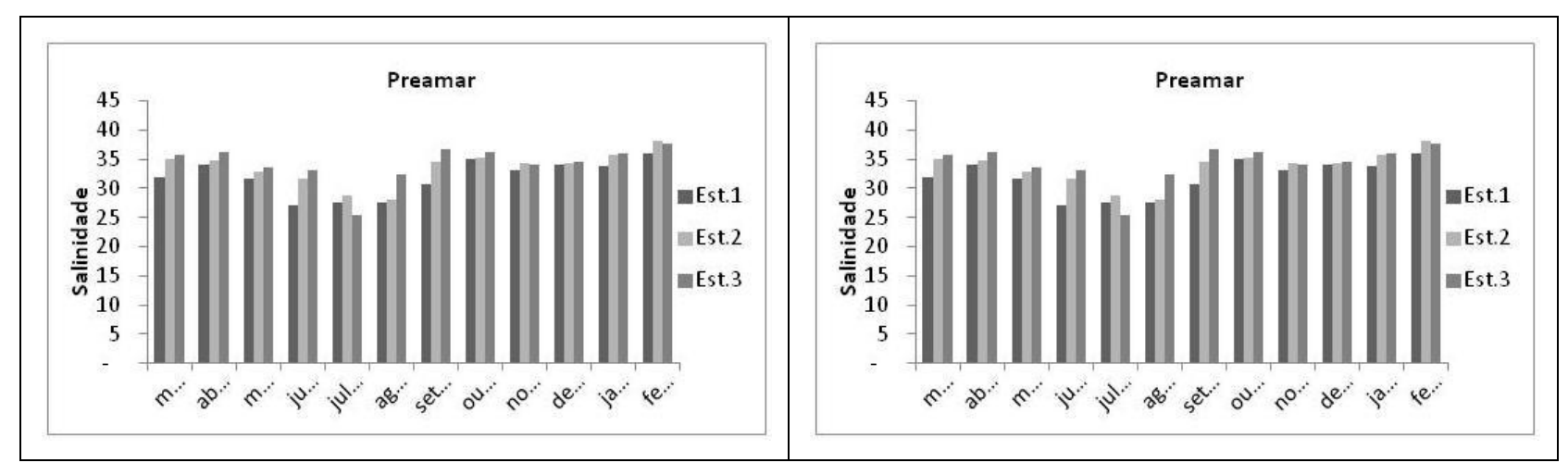

Figura 6 - Variação temporal da salinidade nas estações de coleta 1, 2 e 3 no estuário do rio Carrapicho

\section{Oxigênio Dissolvido e Percentual de Saturação do Oxigênio.}

Os teores de oxigênio dissolvido foram menores em outubro/07 e maiores em agosto/07, ambos na preamar, variando de $2,2 \mathrm{ml} / \mathrm{L}$ na estação 1 (48,4\% de saturação do oxigênio) e 6,2 $\mathrm{ml} / \mathrm{L}$ na estação, (105,5\% de saturação do oxigênio) (Figura 7). A mediana do oxigênio dissolvido e do percentual de saturação do oxigênio no período chuvoso foram, respectivamente, $4,1 \mathrm{ml} / \mathrm{L}$ e $89,02 \%$, e no período de estiagem, 5,2 ml/L e 118,1\% (Tabela 1 ).

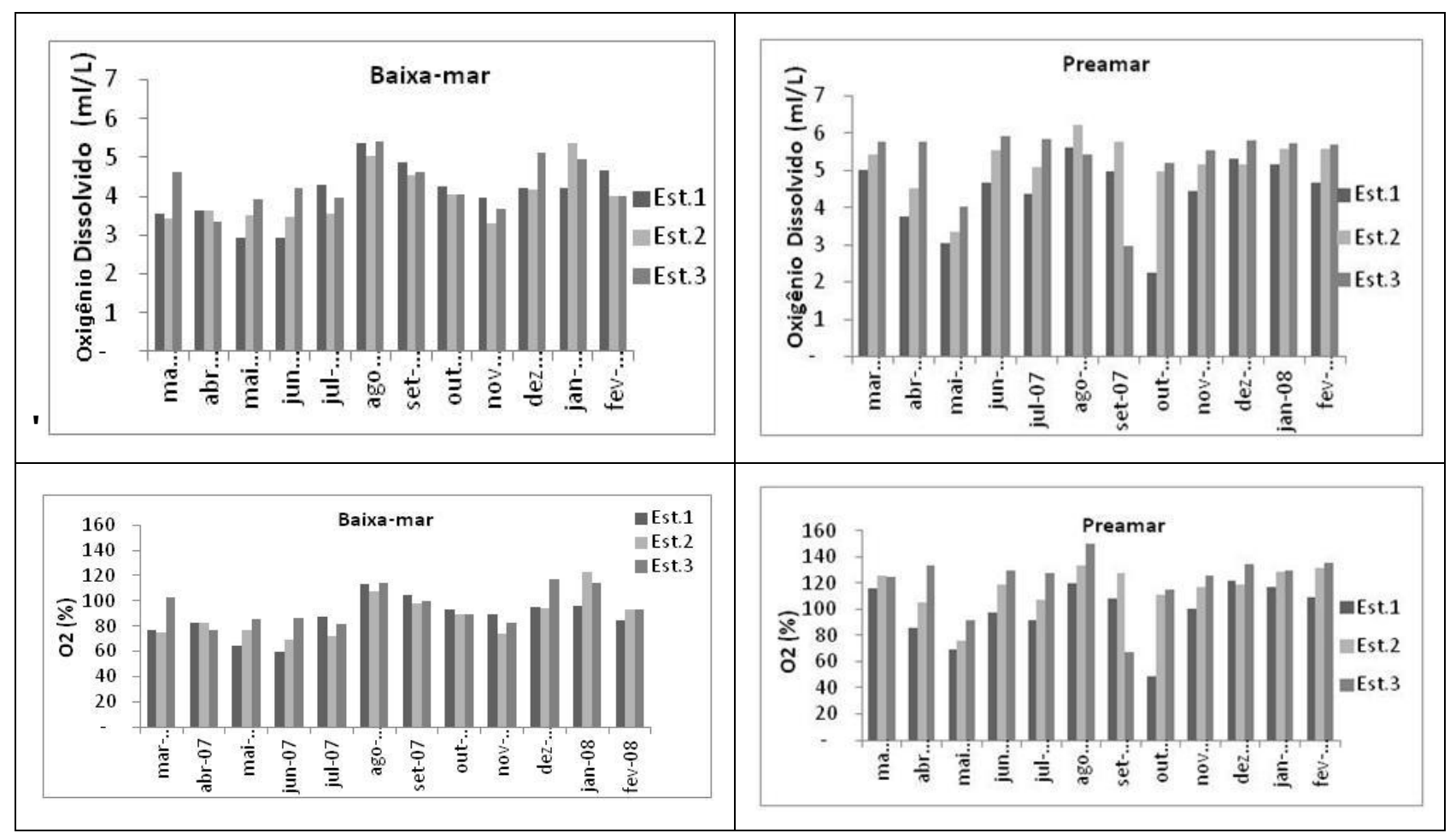

Figura 7 - Variação anual do oxigênio dissolvido nas estações de coleta 1, 2 e 3 no estuário do rio Carrapicho.

pH

Durante o período de estudo os valores do $\mathrm{pH}$ oscilaram entre em 7,8 na estação 1 , em outubro/07, e 8,8 na estação 3, em agosto/07, ambos na preamar (Figura 8). O pH se manteve alcalino tanto espacialmente, sazonalmente e nos estágios de maré. Para o $\mathrm{pH}$, a mediana no período chuvoso foi de 8,2 , e estiagem foi 8,5 ( Tabela 1 ). 


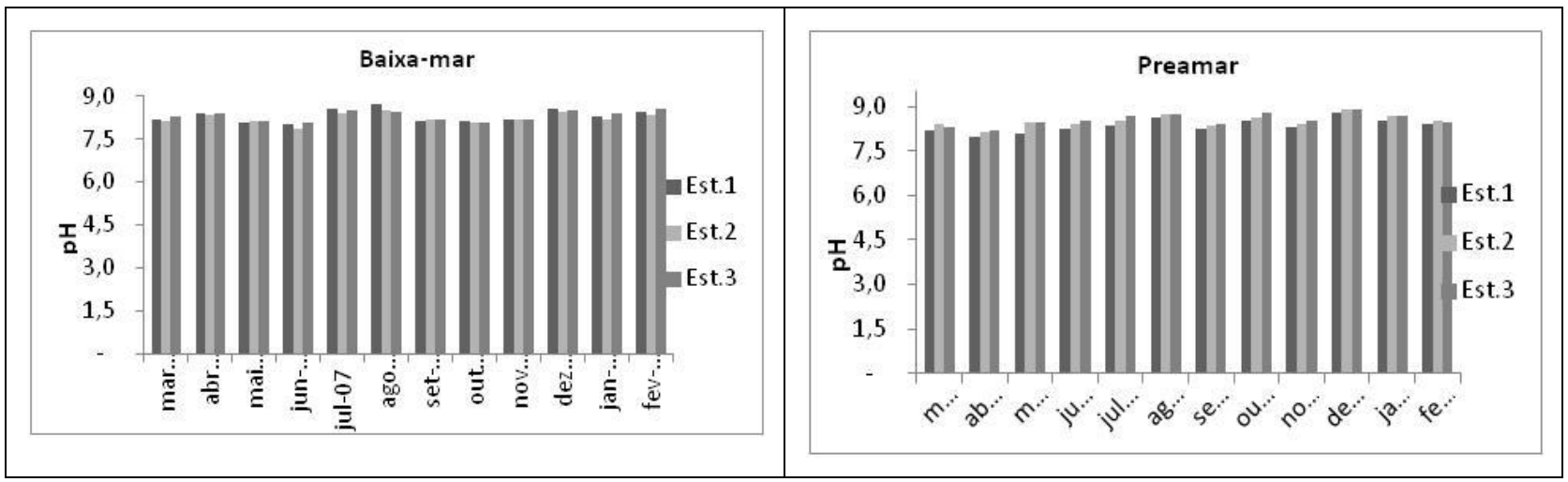

Figura 8 - Variação anual do pH nas estações de coleta 1, 2 e 3 no estuário do rio Carrapicho.

\section{Amônia}

De forma geral, o teor de amônia foi baixo, e sua concentração variou de valores inferiores ao limite de detecção $(0,01 \mu \mathrm{mol} / \mathrm{L})$ nas três estações, em diferentes meses e estágios de maré. O valor máximo de $0,16 \mu \mathrm{mol} / \mathrm{L}$, foi detectado na estação 1 , em junho/07, na preamar (Figura 9). A amônia apresentou um valor para mediana de 0,01 $\mu \mathrm{mol} / \mathrm{L}$ tanto no período de estiagem quanto no chuvoso (Tabela 1).

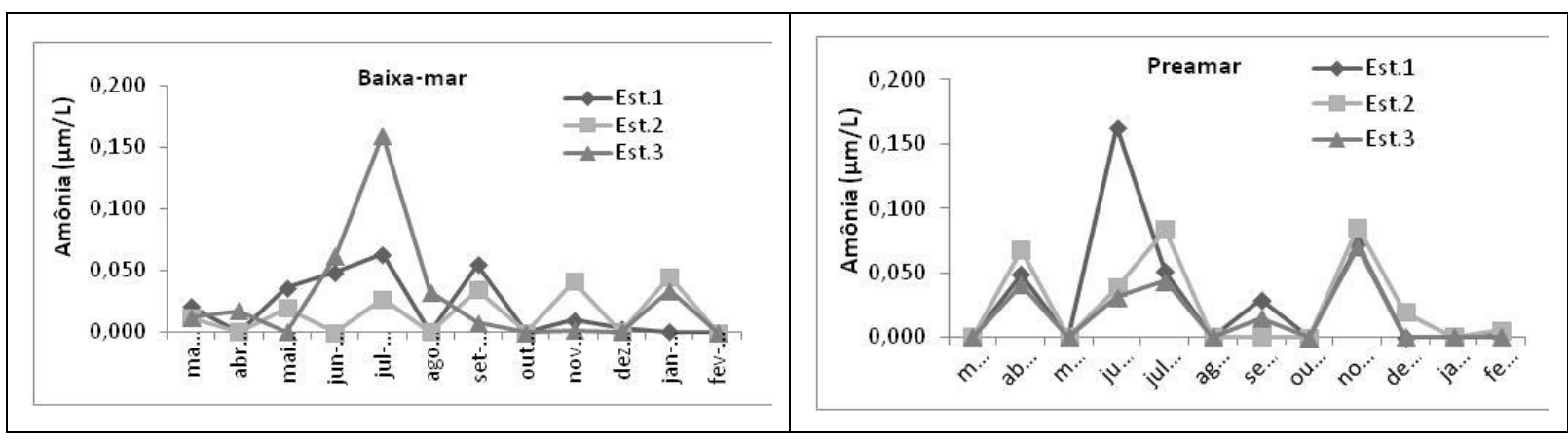

Figura 9 - Variação anual da amônia nas estações de coleta 1, 2 e 3 no estuário do rio Carrapicho.

\section{Nitrito}

O nitrito apresentou também baixos teores durante todo o período estudado, variando de valores não detectados $(0,01 \mu \mathrm{mol} / L)$, nas três estações, nos diferentes meses e estágios de maré a 0,22 $\mu \mathrm{mol} / \mathrm{L}$ na estação 1 , em junho/07 na preamar (Figura 10). O nitrito apresentou valores para mediana de $0,04 \mu \mathrm{mol} / \mathrm{L}$ e $0,01 \mu \mathrm{mol} / \mathrm{L}$, respectivamente para os períodos, chuvoso e de estiagem (Tabela 1).

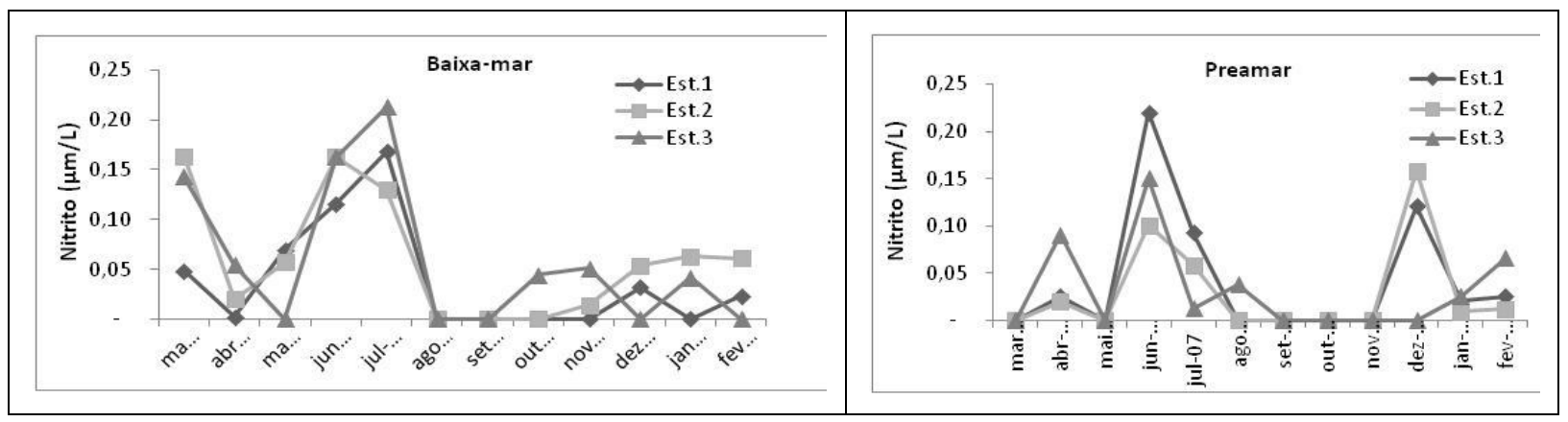

Figura 10 - Variação anual de nitrito nas estações de coleta 1, 2 e 3 no estuário do rio Carrapicho. 
CASTRO, N. F.; FEITOSA, F. A. do N.; FLORES MONTES, M. de J. Avaliação das condições Ambientais do estuário do rio Carrapicho (Itamaracá- PE): Biomassa fitoplanctônica e Hidrologia.

\section{Nitrato}

As concentrações do nitrato foram baixas, seu menor valor foi de $0,06 \mu \mathrm{mol} / \mathrm{L}$ na estação 2 , em novembro/07 na baixa-mar e o maior valor foi de $12,04 \mu \mathrm{mol} / \mathrm{L}$ na estação 1 , em julho/07 na preamar (Figura 11). Observou-se, para o nitrato, uma mediana no período chuvoso de 1,04 $\mathrm{mol} / \mathrm{L}$, e estiagem de 1,5 $\mu \mathrm{mol} / \mathrm{L}$ (Tabela1).

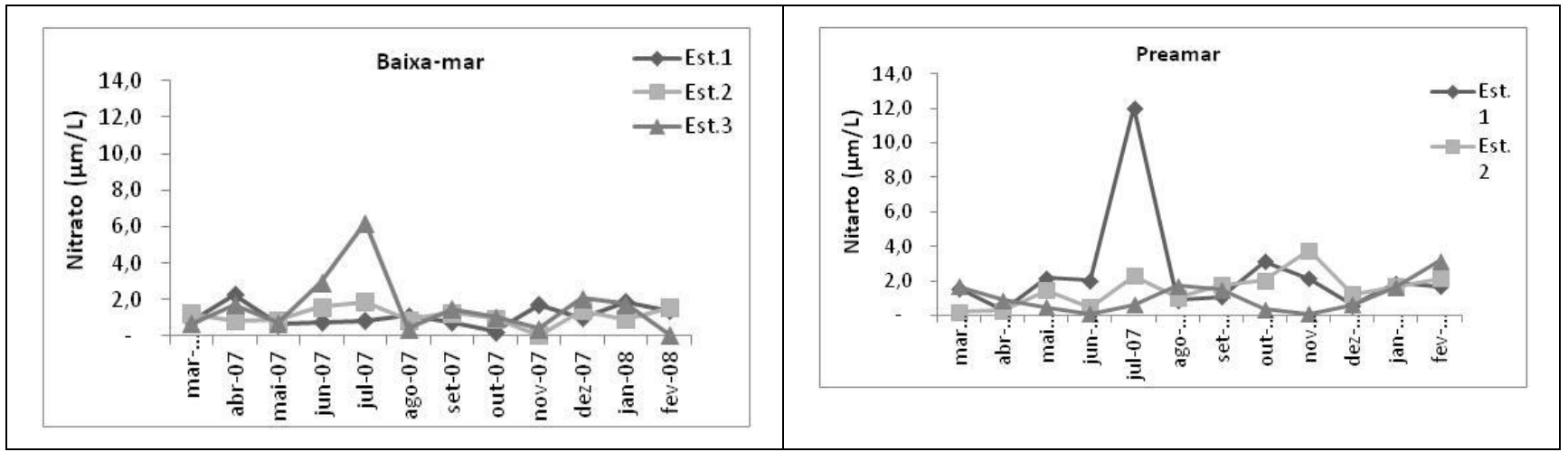

Figura 11 - Variação anual de nitrato nas estações de coleta 1, 2 e 3 no estuário do rio

\section{Fosfato} Carrapicho.

As concentrações de fosfato variaram de valores não detectados $(0,01 \mu \mathrm{mol} / \mathrm{L})$ nas estações 2 e 3, em julho/07 na preamar a 1,9 $\mu \mathrm{mol} / \mathrm{L}$ na estação 3, em julho/07 na baixa-mar (Figura 12). De uma forma geral, os valores de fosfato foram baixos no decorrer do período estudado. O fosfato apresentou uma mediana tanto no período chuvoso, quanto estiagem, de $0,46 \mu \mathrm{mol} / \mathrm{L}$ (Tabela 1 ).
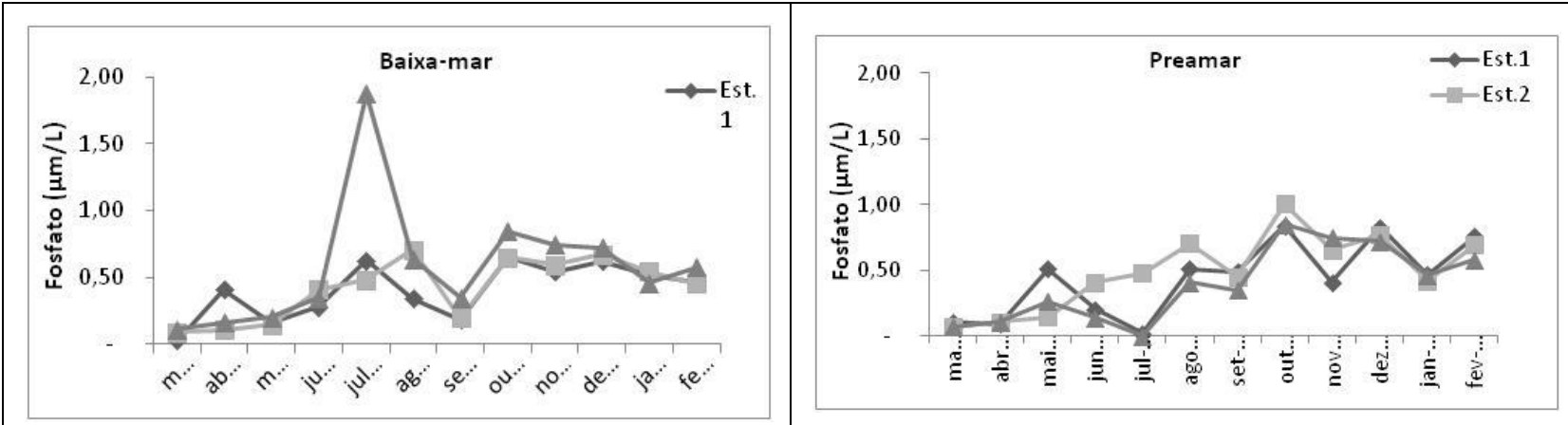

Figura 12 - Variação anual do fosfato nas estações de coleta 1, 2 e 3 no estuário do rio Carrapicho.

\section{Silicato}

As concentrações de silicato variaram de $1,3 \mu \mathrm{mol} / \mathrm{L}$ na estação 3 , em janeiro/08 na baixa-mar a $47 \mu \mathrm{mol} / \mathrm{L}$ na estação 1, em maio/07 na preamar (Figura 13). Observou-se, para 0 silicato, uma mediana no período chuvoso de 13,9 $\mu \mathrm{mol} / \mathrm{L}$, e estiagem de 10,7 $\mathrm{mmol} / \mathrm{L}$ (Tabela 1). 


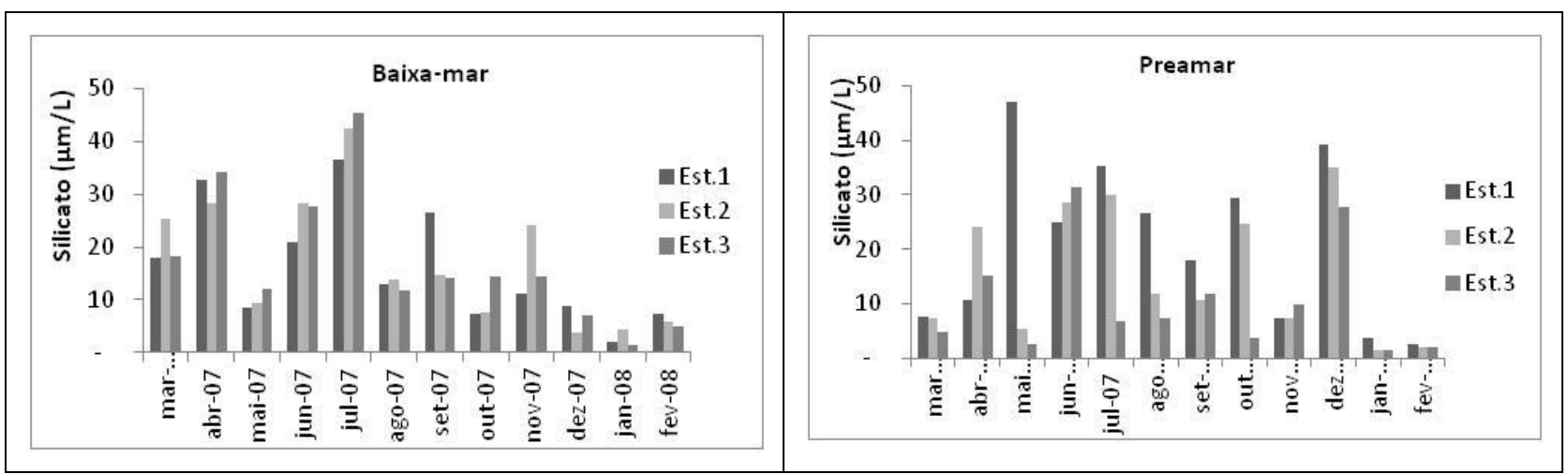

Figura 13 - Variação anual do silicato nas estações de coleta 1, 2 e 3 no estuário do rio Carrapicho.

\section{Material Particulado em Suspensão (MPS)}

Durante o período estudado seus valores do MPS oscilaram entre $3 \mathrm{mg} / \mathrm{L}$, na estação 2 , em novembro/07 na baixa mar, e $63 \mathrm{mg} / \mathrm{L}$, na estação 2, em fevereiro/08 na baixa-mar (Figura 14). O material particulado em suspensão apresentou uma mediana no período chuvoso de 39 $\mathrm{mg} / \mathrm{L}$, estiagem de $34 \mathrm{mg} / \mathrm{L}$ (Tabela 1 ).

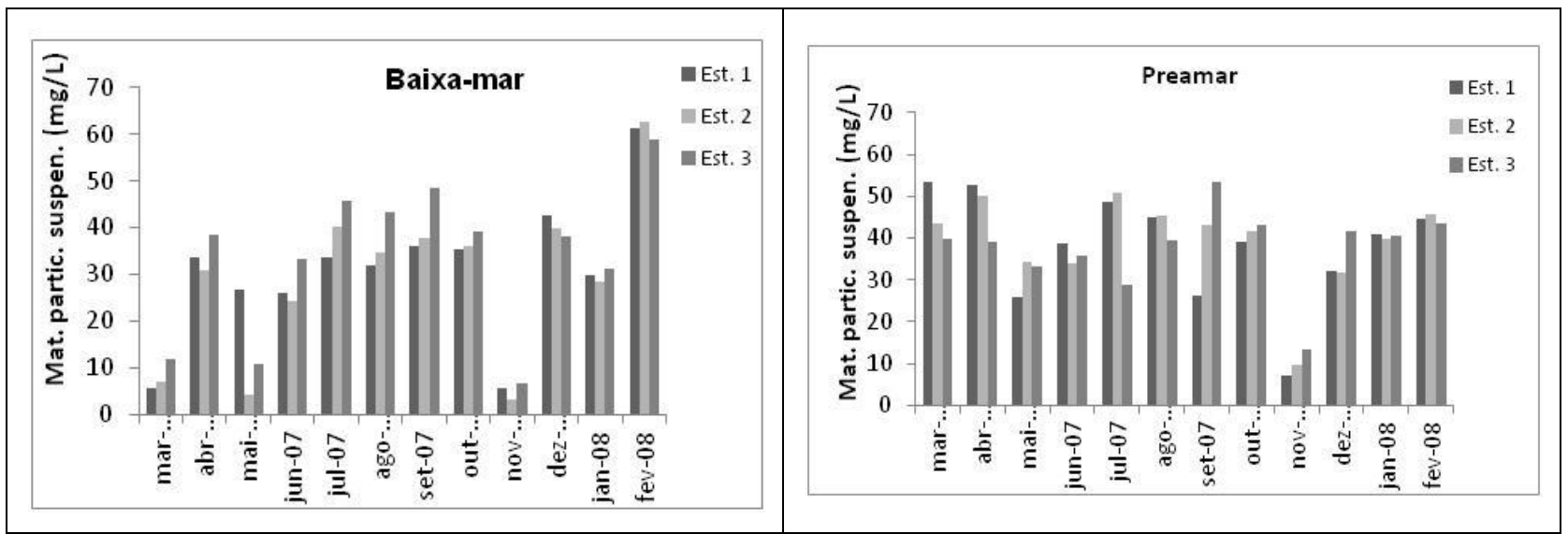

Figura 14 - Variação anual do material particulado em suspensão nas estações de coleta 1, 2 e 3 no estuário do rio Carrapicho.

\section{Biomassa Fitoplanctônica}

A concentração da clorofila a variou de $2,3 \mathrm{mg} \cdot \mathrm{m}^{-3}$ na estação 3 , em janeiro/08 na preamar a $40 \mathrm{mg} \cdot \mathrm{m}^{-3}$ na estação 3 , em julho/07 na baixa mar. Observou-se um gradiente crescente do ponto 3 ao 1 de abril a dezembro/07 na preamar (Figura 15). A clorofila a apresentou uma mediana no período chuvoso de $10,1 \mathrm{mg} \cdot \mathrm{m}^{-3}$, e estiagem de $7,5 \mathrm{mg} \cdot \mathrm{m}^{-3}$ (Tabela 1).

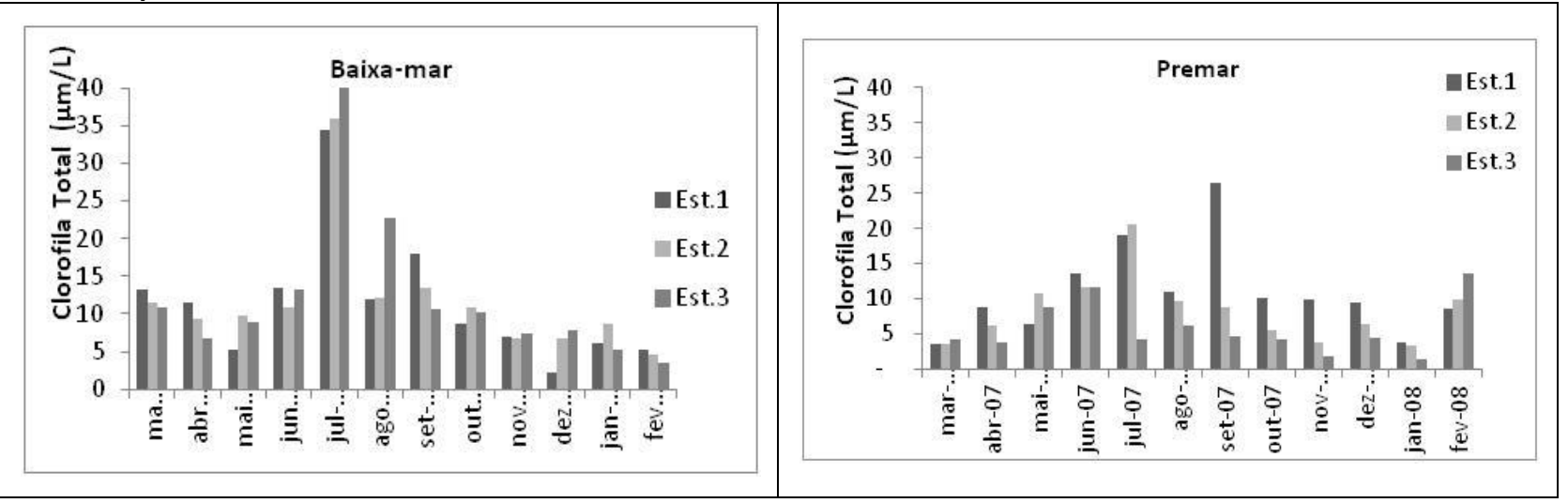


CASTRO, N. F.; FEITOSA, F. A. do N.; FLORES MONTES, M. de J. Avaliação das condições Ambientais do estuário do rio Carrapicho (Itamaracá- PE): Biomassa fitoplanctônica e Hidrologia.

Figura 15 - Variação anual da clorofila total nas estações de coleta 1, 2 e 3 no estuário do rio Carrapicho.

Tabela 1 - Valores mínimos, máximos e medianas das variáveis ambientais no estuário do rio Carrapicho (Itamaracá - PE).

\begin{tabular}{lrrrrrr}
\hline \multicolumn{1}{c}{ Parâmetros } & \multicolumn{3}{c}{ Chuvoso } & & \multicolumn{3}{c}{ Estiagem } \\
& Min. & Max. & Mediana & Min. & Max. & Mediana \\
\hline Pluviosidade 2007/2008 & 83,50 & 390,80 & 217,50 & 25,60 & 331,0 & 83,50 \\
(mm) & 2,60 & 16,00 & 5,40 & 2,60 & 25,00 & 7,10 \\
Profundidade (m) & 10,00 & 2,80 & 2,00 & 1,00 & 3,50 & 1,50 \\
Transparência (m) & 26,50 & 30,00 & 29,30 & 26,00 & 31,0 & 29,50 \\
Temperatura ( $\left.{ }^{\circ} \mathrm{C}\right)$ & 20,20 & 36,10 & 31,70 & 30,40 & 38,20 & 34,00 \\
Salinidade & 59,40 & 150,50 & 89,00 & 48,40 & 135,10 & 118,10 \\
Taxa Saturação O2 (\%) & 2,90 & 6,20 & 4,10 & 2,20 & 5,80 & 5,20 \\
Oxigênio Dissolvido (ml/L) & 0,01 & 0,16 & 0,01 & 0,01 & 0,09 & 0,01 \\
Amônia $\mu \mathrm{m} / \mathrm{L}$ & 0,01 & 0,22 & 0,04 & 0,01 & 0,16 & 0,01 \\
Nitrito $\mu \mathrm{m} / \mathrm{L}$ & 0,08 & 12,04 & 1,04 & 0,06 & 3,77 & 1,50 \\
Nitrato $\mu \mathrm{m} / \mathrm{L}$ & 0,01 & 1,90 & 0,46 & 0,19 & 1,00 & 0,46 \\
Fosfato $\mu \mathrm{m} / \mathrm{L}$ & 2,60 & 47,0 & 13,90 & 1,30 & 39,1 & 10,70 \\
Silicato $\mu \mathrm{m} / \mathrm{L}$ & 7,80 & 8,70 & 8,20 & 8,00 & 8,80 & 8,50 \\
pH & 3,60 & 40,00 & 10,10 & 2,30 & 26,40 & 7,50 \\
Clorofila a (mg.m-3) & 6,00 & 53,00 & 39,00 & 3,00 & 63,00 & 34,00 \\
Mat. Part. Suspensão (mg/L) & & & & & & \\
\hline
\end{tabular}

\section{PERMANOVA}

Foram encontradas diferenças significativas durante a realização deste teste, entre os três fatores analisados: Estações de coleta (Est. 1, 2 e 3), sazonalidade (chuvoso e estiagem) e maré (Baixa-mar e Preamar) com Pseudo- $F=2.50,8.32$ e 17.82, e $p<0.05,<0.01$ e $<0.01$, respectivamente. Também foi encontrada uma interação significativa entre os fatores sazonalidade e maré com Pseudo- $F=2.85$ e $p<0.05$. Durante as comparações post-hoc se observou uma diferença significativa entre as estações 1 e $3 \mathrm{com} t=2.13$ e $p<0.01$, e entre o período chuvoso e estiagem apenas durante a maré baixa com $t=3.28$ e $p<0.01$ (Tabela 2).

Tabela 2 - Análise estatística (PERMANOVA) no estuário do rio Carrapicho (Itamaracá - PE).

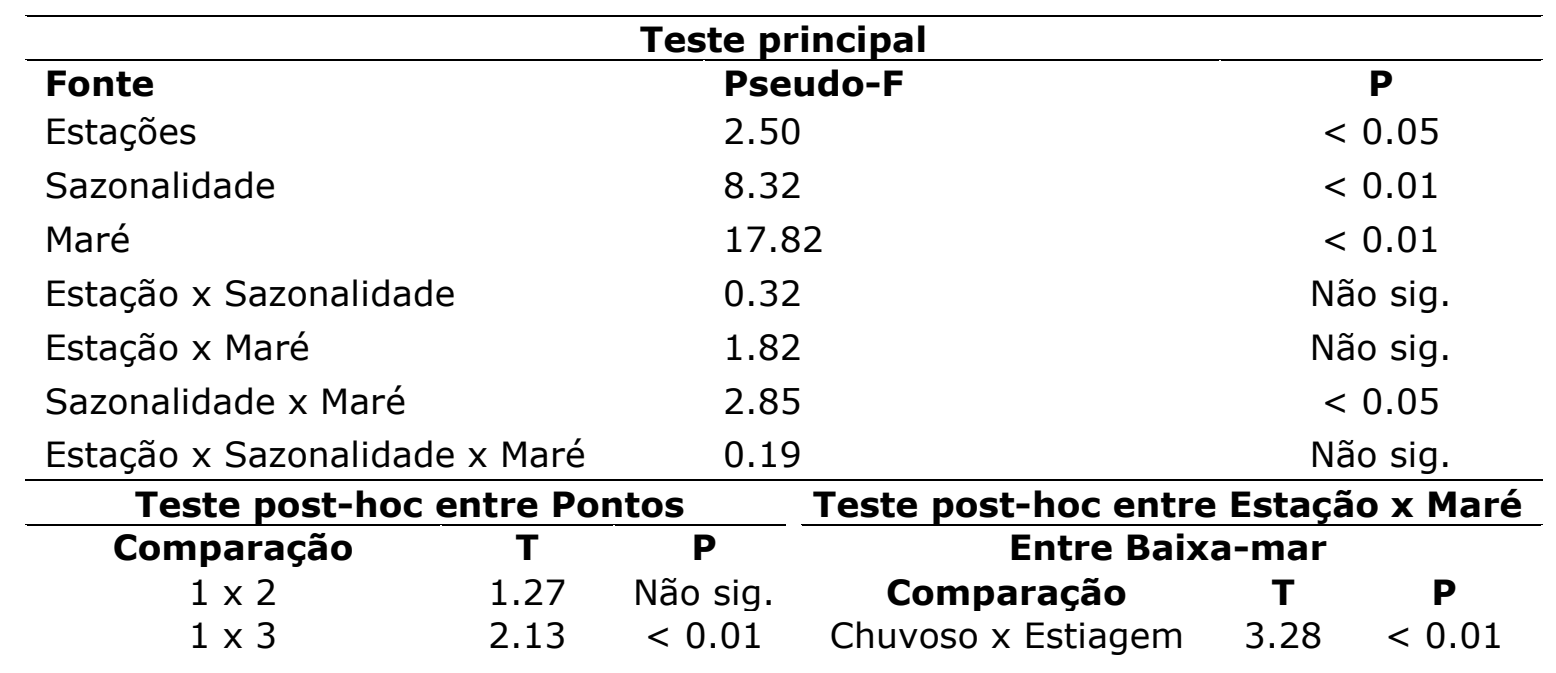


CASTRO, N. F.; FEITOSA, F. A. do N.; FLORES MONTES, M. de J. Avaliação das condições Ambientais do estuário do rio Carrapicho (Itamaracá- PE): Biomassa fitoplanctônica e Hidrologia.

\begin{tabular}{|c|c|c|c|c|c|}
\hline \multirow[t]{2}{*}{$2 \times 3$} & \multirow{2}{*}{1.05} & \multirow{2}{*}{ Não sig. } & \multicolumn{3}{|c|}{ Entre Preamar } \\
\hline & & & $\begin{array}{c}\text { Comparação } \\
\text { Chuvoso x Estiagem }\end{array}$ & $\begin{array}{c}\mathbf{T} \\
1.08\end{array}$ & $\begin{array}{c}\mathbf{P} \\
\text { Não sig. }\end{array}$ \\
\hline
\end{tabular}

\section{DISCUSSÃO}

Estuários e lagoas costeiras têm importância fundamental para a manutenção da biodiversidade aquática. Trata-se de regiões de transição com alta produtividade biológica e teias alimentares que utilizam várias alternativas. Além disso, são sistemas submetidos a inúmeros impactos, especialmente os resultantes de ação antrópica (TUNDISI; TUNDISI, 2008).

Os principais fatores que tem fundamental importância no controle da produção primária nos ecossistemas aquáticos são os climatológicos, como o input de energia radiante e precipitação total; e, os hidrológicos como penetração de luz, a estrutura térmica da coluna d'água, o grau de mistura do ecossistema e o suprimento e dinâmica dos nutrientes inorgânicos (TUNDISI; TUNDISI, 1976).

De acordo com Braga (1999), os aportes de compostos dissolvidos via drenagem continental e precipitação atmosférica podem modificar temporariamente as concentrações de certas substâncias químicas da água do mar, principalmente os sais nutrientes, fornecendo condições para a produção primária "nova" do fitoplâncton. As águas dos rios e das chuvas possuem concentrações de nitrito, nitrato, amônia, fosfato e silicato variáveis, mas frequentemente maiores que aquelas encontradas nas águas de superfície do mar. A receptação pluviométrica contribui de forma considerável no transporte de substâncias do continente para a zona costeira, e particularmente, nos estuários, influencia tanto na biomassa como na produtividade primária.

No estuário do rio Carrapicho a pluviosidade destacou-se como a forçante física que mais interferiu no sistema, provocando alterações em vários parâmetros, como aumento no período chuvoso das concentrações dos nutrientes, exceto fosfato, da clorofila a, material particulado em suspensão, e com redução da salinidade, transparência, temperatura e pH. Este padrão também foi observado em outros estuários como no rio Jaguaribe (PE) por Santos et al. (2000); no complexo lagunar estuarino Mundaú/Manguaba (AL), por Melo-Magalhães et al. (2004); no rio Mossoró (RN), por Medeiros et al. (2010); e na área portuária do Recife por Paulo et al. (2011).

De forma geral, a profundidade local no estuário do rio Carrapicho foi considerada rasa, no entanto, o ponto 3 por estar inserido no Canal de Santa Cruz, foi significativamente mais profundo do que os demais. O fato de prevalecer baixa profundidade no referido estuário, presume-se que houve maior interação entre o sedimento e a coluna d'água.

Por outro lado, a temperatura tem uma ação direta sobre a periodicidade e distribuição dos organismos aquáticos. Assume grande importância na produtividade biológica da água, cujos ritmos dependem dela, sendo considerado um dos fatores ecológicos decisivos dentro dos sistemas e o principal fator limitante da distribuição geográfica de muitas espécies vegetais e animais, influência também na taxa de fotossíntese e na respiração dos organismos aquáticos (SIPAUBA-TAVARES, 1998).

Em regiões tropicais, de acordo com Passavante e Feitosa (2004), a temperatura apresenta pouca variação podendo aparentar uma discreta influência em organismos fitoplactônicos, porém seu efeito sinergético com outros parâmetros ambientais é de importância para estes vegetais.

No estuário do rio Carrapicho a temperatura apresentou pouca diferença sazonal e espacial, com uma amplitude de $5^{\circ} \mathrm{C}$, não sendo observada uma correlação significativa com as demais variáveis. Como era de se esperar a temperatura foi mais baixa no período chuvoso do que no período de estiagem. Essa pequena variação de temperatura é comum em estuários tropicais, como é o caso do canal de Santa Cruz (PORTO-NETO, 1998; GALDINO, 2004).

$\mathrm{Na}$ zona costeira marinha, os estuários destacam-se por apresentar menores índices de transparência da água, como consequência da influência continental mais evidenciada no 
CASTRO, N. F.; FEITOSA, F. A. do N.; FLORES MONTES, M. de J. Avaliação das condições Ambientais do estuário do rio Carrapicho (Itamaracá- PE): Biomassa fitoplanctônica e Hidrologia.

período chuvoso. A transparência da água é uma variável física dependente da precipitação de chuvas nas áreas estuarinas.

O rio Carrapicho mostrou um gradiente crescente de transparência da água de montante para a jusante, o que deve ter facilitado o desenvolvimento da comunidade fitoplactônica, por haver maior disponibilidade da camada eufótica. Tais índices de transparência estão dentro do padrão considerado normal para um ambiente estuarino como observado na Barra das Jangadas, por Branco et al.(2006); rio Ariquindá, por Grego et al. (2009); no rio Maracaípe, por Bastos et al. (2011); e na área portuária do Recife, por Paulo et al. (2011).

Flores-Montes (1996), no Canal de santa Cruz, registrou para a salinidade um comportamento conservativo, ou seja, não foi produzida ou consumida dentro do sistema, apenas diluída. Esta característica permite que a intrusão salina tenha uma influência intermitente, maior na preamar e menor na baixa-mar, permitindo monitorar a dinâmica salina ao longo de um estuário e suas interações hidrológicas.

A característica fundamental das áreas estuarinas é a variação da salinidade. As principais fontes geradoras destas variações são as marés, a evaporação e o fluxo de água doce dos rios que desaguam nestes ambientes.

$\mathrm{Na}$ área estudada, a salinidade apresentou um padrão sazonal definido com valores mais elevados no período de estiagem (maior intensidade de irradiação solar e consequente evaporação), e na preamar em função da maior influência marinha. Este padrão também foi observado na Barra de Orange e Catuama por Figueiredo et al. (2006); no mesmo rio estudado, por Santos et al. (2009); no Lago Salino Central, por Echaniz (2011). Observou-se que nas preamares, mesmo no período de maior pluviosidade, os índices de chuvas não foram suficientes para modificar de forma brusca a salinidade. Este fato pode ser considerado indicativo da forte influência das águas costeiras no referido estuário como consequência da grande intrusão marinha na preamar.

Outro componente químico importante para os processos bioquímicos e biológicos é o oxigênio dissolvido na água, pois este tem ação direta no metabolismo dos organismos, como por exemplo, na respiração, bem como participa dos processos de oxigenação da matéria orgânica e de compostos químicos como amônia-N e o nitrito-N (SILVA, 2003). Além disso, segundo Flores-Montes (1996), é um importante indicador de áreas poluídas, uma vez que, baixas concentrações poderão indicar uma poluição química, física ou orgânica, e valores muito elevados podem indicar processos de eutrofização.

A concentração de oxigênio dissolvido no ambiente estudado apresentou pouca variação sazonal. Durante a preamar observou-se uma tendência na distribuição espacial com um gradiente de concentração crescente da parte interna para a foz do rio, estes maiores valores podem ser explicados devido a maior oxigenação da água oriunda da zona costeira. O mesmo foi observado na Bacia do Pina, por Santos et al. (2009); nas áreas costeiras de São José de Ribamar, Cedral e Cajapió, por Rodrigues e Cutrim (2010).

Macêdo e Costa (1978) apresentaram um sistema de classificação para águas estuarinas no nordeste Brasil baseando no teor de saturação do oxigênio: zona saturada - com teores de saturação acima de 100\%; zona de baixa saturação - com teores de saturação entre 50 a 100\%; zona semi-poluída - Com teores de saturação entre 25 e 50\%; zona poluída - com teores de saturação abaixo de $25 \%$.

Levando-se em consideração o sistema de classificação acima, verificou-se que o estuário do rio Carrapicho encontra-se isento de poluição orgânica, tendo em vista que a mediana dos períodos, chuvoso e estiagem, evidenciou valores acima de $80 \%$. Esse padrão também foi observado no estuário do rio Una, por Bastos et al. (2002), e na zona costeira Tropical (Ipojuca-PE), por Bastos et al. (2011).

Segundo Cavalcanti (2003), o pH da água é de fundamental importância para as demais variáveis químicas de interesse ambiental, por exemplo, alcalinidade e dióxido de carbono (CO2), podendo ser utilizado como indicador de possíveis alterações fisiológicas dos organismos. 
CASTRO, N. F.; FEITOSA, F. A. do N.; FLORES MONTES, M. de J. Avaliação das condições Ambientais do estuário do rio Carrapicho (Itamaracá- PE): Biomassa fitoplanctônica e Hidrologia.

$\mathrm{O} \mathrm{pH}$ no rio Carrapicho se manteve alcalino tanto espacial como sazonalmente, e nos estágios de maré. O mesmo foi observado em Barras das Jangadas, por Branco (2001); no rio Formoso, por Honorato da Silva (2003); no rio Timbó, por Grego et al. (2004).

Já em relação aos nutrientes dissolvidos, segundo Braga (1999), o estudo da dinâmica destes sais serve como um bom indicador das relações abióticas e bióticas que ocorrem em águas marinhas tropicais.

Os nutrientes são considerados limitantes para a produtividade primária por serem vitais para a vida vegetal.

No rio Carrapicho as concentrações de nitrito, nitrato e silicato estiveram mais elevadas no período chuvoso, em consequência das chuvas e lixiviação do solo, o mesmo não foi observado para o fosfato e amônia, que segundo a mediana não demonstrou variação.

Tendo em vista que o rio estudado é considerado litorâneo de planície e sofre forte influência da maré, Ihe confere as condições de baixas concentrações destes nutrientes. Por outro, lado esses baixos níveis de sais dissolvidos associado com altas taxas de saturação de oxigênio e baixas concentrações de clorofila a indicam tratar-se de um estuário ainda isento do processo de eutrofização.

As concentrações dos nutrientes quando comparadas com outros estuários, também permitiram caracterizar o ecossistema como um ambiente ainda não poluído, segundo Aminot e Chaussepied (1983), os quais reportaram como valores máximos para áreas estuarinas não impactadas até $1.00 \mu \mathrm{M}$ para nitrito e fosfato e $15,00 \mu \mathrm{M}$ para o nitrato.

Áreas com baixas concentrações destes nutrientes também foram observadas no rio Mamucaba e Ilhetas, por Losada et al. (2003); na Lagoa dos Patos, por Fujita e Odebrecht (2007); e no rio Ariquindá, por Grego et al. (2009). Por outro lado, ecossistemas com altas concentrações de nutrientes, caracterizando ambientes poluídos, associados ao desenvolvimento urbano, industrial e atividades agrícolas, foram reportadas nos estuários da bacia do Pina (Brasil) por Feitosa et al. (1999), e do rio Tamsui (Taiwan) por Wu e Chou (2003).

O silicato mostrou uma relação direta com a clorofila a possivelmente pelo fato do grupo dominante na área ser o das diatomáceas o que evidencia a importância deste nutriente para o crescimento da biomassa fitoplanctônica deste ambiente.

Wu e Chou (2003) no estuário do rio Tamsui (Taiwan) relataram que o enriquecimento com silicato tem elevado notavelmente a produção fitoplanctônica, principalmente das diatomáceas, do que enriquecimentos de nitrogênio ou fósforo, os autores relataram ainda uma correlação direta entre o nutriente e a biomassa das microalgas.

No entanto, pode ser visualizada também relação inversa do silicato com a biomassa fitoplanctônica, como o observado por Aktan et al. (2005) na baía de Ízmit (Turquia), onde os autores associaram a pouca disponibilidade do nutriente no período de estiagem e ao consumo realizado pelas diatomáceas.

Em relação ao material particulado em suspensão no estuário do rio Carrapicho, não ficou bem diferenciado em termos de sazonalidade e sendo típico de um rio litorâneo de planície, cuja capacidade de transporte de sedimento é relativamente baixa. O mesmo padrão foi observado em outros estuários da região nordeste do Brasil por Losada et al. (2003), no Ilhetas e Mamucabas (PE); no Ariquindá (PE), por Grego et al. (2009), no estuário do rio Maracaípe (PE), por Bastos et al. (2011); e no estuário do rio Caravelas (BA) por Schettini et al. (2010).

Os trabalhos sobre variação espaço-temporal da clorofila a são de grande importância ecológica, pois permitem avaliar o potencial de produção orgânica dos ecossistemas aquáticos, podendo fornecer indicações sobre a quantidade de matéria orgânica disponível aos demais níveis tróficos (PASSAVATE et al., 1987/89)

A capacidade das células do fitoplâncton de sintetizar matéria orgânica depende da disponibilidade de carbono, nitrogênio e fósforo no meio, desta forma a produção da biomassa fitoplanctônica e produtividade refletem as condições de oligotrofia, mesotrofia e eutrofia da água e constituem bons indicadores de alterações ambientais (FRANCO et al., 2006). Neste 
CASTRO, N. F.; FEITOSA, F. A. do N.; FLORES MONTES, M. de J. Avaliação das condições Ambientais do estuário do rio Carrapicho (Itamaracá- PE): Biomassa fitoplanctônica e Hidrologia.

sentido, taxas de clorofila a e produtividade fitoplanctônica têm sido incluídas como um dos componentes de estados tróficos para avaliações de ecossistemas aquáticos (SMITH, 2007).

No estuário do rio Carrapicho os teores de clorofila a foram típicos de áreas costeiras que não vêm sofrendo com lançamento de efluentes domésticos e industriais. Ficando bem evidenciado maiores concentração no período chuvoso e na baixa-mar. Portanto, pode-se presumir que houve uma relação direta entre a clorofila a e os nutrientes, exceto fosfato.

Levando-se em consideração a mediana dos períodos chuvoso e estiagem, as concentrações de clorofila a ficaram inferiores a $11,0 \mathrm{mg} \cdot \mathrm{m}^{-3}$, sendo indicativo de um ambiente ainda livre do processo de eutrofização. Resultados compatíveis ao do presente trabalho foram observados por Losada et al. (2003), nos estuários dos rios Ilheta e Mamucaba; por Grego et al. (2009), no estuário do rio Arinquindá (PE); por Pereira-Filho et al. (2010), no rio Itajaí-Açú (SC), e por Bastos et al. (2011), no estuário do rio Maracaípe.

Por outro lado, elevados índices de clorofila a em estuários considerados fortemente impactados foram registrado por Grego et al. (2004), no rio Timbó com teores de clorofila a $160,39 \mathrm{mg} \cdot \mathrm{m}^{-3}$; por Santos et al (2009), na bacia do Pina com valores de clorofila a de 210 $\mathrm{mg} \cdot \mathrm{m}^{-3}$; por Paulo (2011), na área portuária do Recife com teores de $164 \mathrm{mg} \cdot \mathrm{m}^{-3}$.

\section{CONCLUSÕES}

1. A forçante física pluviosidade foi fator condicionante no estuário do rio Carrapicho sendo responsável por várias mudanças nas variáveis ambientais analisadas;

2. O rio Carrapicho apresentou um gradiente de salinidade decrescente de jusante pra montante, com um regime variando de polihalino a euhalino e sofrer forte influência de águas costeiras;

3. O rio Carrapicho por ser considerado do tipo litorâneo de planície demonstrou baixa capacidade de transporte de sedimento para a zona costeira marinha;

4. As baixas concentrações de nutrientes dissolvidos, clorofila a e a elevada taxa de saturação do oxigênio dissolvido indicam tratar-se de um ambiente ainda isento do processo de eutrofização;

5. A análise estatística evidenciou que o ambiente estudado possui variações espaciais, sazonais e estágios de maré em relação às variáveis ambientais.

\section{AGRADECIMENTOS}

Os autores deste trabalho gostariam de agradecer ao CNPq pelo apoio financeiro do Projeto de Pesquisa através do processo n 48458/2006-6.

\section{BIBLIOGRAFIA}

AKTAN, Y.; TÜFEKCV, I.; AYKULU, G. Distribution patterns, biomass estimates and diversity of phytoplankton in İzmit Bay (Turkey). Estuar. Coast. Shelf Sci. v. p. 372384, 2005.

AMINOT, A.; CHAUSSEPIED, M. Manuel des analyses chimiques en milieu marin. CNEXO, Brest. 1983. p.395.

BASTOS, R. B. Variação espaço temporal da biomassa fitoplanctônica relacionada com parâmetros abióticos no estuário do rio Una (Pernambuco - Brasil). Monografia (graduação em Biologia) Centro de Ciências Biológicas, Universidade Federal de Pernambuco. Recife, 2002. p.56f.

BASTOS, R. B.; FEITOSA, F. A. N.; KOENING, M. L.; MACHADO, R. C.A.; MUNIZ, K. Caracterização de uma zona costeira tropical (Ipojuca, Pernambuco, Brasil): Produtividade fitoplanctônica e outras variáveis ambientais. Braz. J. Aquat. Sci. Technol. v.15,n.1, p.1-10, 2011.

BAUMgARTEN, M. G. Z.; NIENCHESKI, L. F. H. Gravitimetria. Manual de análises em oceanografia química. Rio Grande Do Sul, 1996. p.19-54. 
BRAGA, E. S. Sasonal variaton of atmospheric and terrestrial nutrientes and their influence on primary production in na oligotropic costal systemsouthern Brazil. Revista Brasileira de Oceanografia. São Paulo, v. 47, n. 1, p.47-57, 1999.

BRANCO, E. S. Aspectos ecológicos da comunidade fitoplanctônica no sitema estuarino de Barra das Jangadas (Jaboatão dos Guararapes - Pernambuco - Brasil). Dissertação (Mestrado) Universidade Federal de Pernambuco. Recife, 2001. p.125.

BRANCO, E. S.; FEITOSA, F. A. N.; SILVA-CUNHA, H. G. G.; NEUMANN-LEITÂO, S.; VITORIA, U. S. R. Variação sazonal das algas planctônicas correlacionadas com parânmetros ambientais no estuário da Barras das Jangadas ( Jaboatão dos Guararapes, PE, Brasil). v. 14, n. 2, p. 17-23, 2006.

CAVALCANTI, L. B. Variações das condições hidrológicas e da clorofila a associadas ao cultivo do camarão marinho Litopenaeus vannamei ( BOnne, 1931), na região estuarina do rio Paraíba do Norte ( Paraíba - Brasil). Tese (Doutorado em Oceanografia) Departamento de Oceanografia. Centro de Tecnologia e Geociências. Universidade Federal de Pernambuco, Recife. 2003. p.146.

CPRH (Agência Estadual de Meio Ambiente) www. Cprh.pe.gov. br, acessado em abril de 2013.

ECHANIZ, S. A.; VIGNATT, A. M. Seasonal variation and influence of turbidity and salinity on the zooplankton of saline lake in central Argentina. Tat. Am. J. Agual. Res. v. 39, n2, p. 306-315, 2011.

ESKINAZI-LEÇA, E.; KOENING, M. L.; SILVA-CUNHA ,M. G. G. o fitoplâncton: estrutura e produtividade. In: Gerenciamento participativo de estuários e manguezais. Recife, 2000. p. 67-74.

FEITOSA, F. A. N., NASCIMENTO, F. C. R.; COSTA, K. M. P. Distribuição espacial e temporal da biomassa fitoplanctônica relacionada com parâmetros hidrológicos na Bacia do Pina (Recife, PE). Trab. Oceanogr. Univ. Fed. Pe. Recife, v.27, p.1-13, 1999.

FIGUEIRERO, J. A.; MUNIZ, K.; MACÊDO, S. J.; FLORES-MONTES, M. J.; FEITOSA, F. A. N. Hidrologia e biomassa fitoplanctônica nas barras Orange e Catuama (Canal de Santa Cruz), em Itamaracá-PE: variação nictemeral. Arquivos de Ciências do Mar. v. 39, p.5$17,2006$.

FLORES-MONTES, M. J. Variação nictemeral do fitoplâncton e parâmetros hidrológicos no Canal de Santa Cruz, Itamaracá - PE. Dissertação (Mestrado) Universidade Federal de Pernambuco. Recife, 1996. p.197.

FRANCO, V. G.; CABEÇADAS, M. N. Produtividade primária no estuário do Tejo e zona costeira adjacente. In: Anais da I Conferencia Lusófona sobre o Sistema Terra - CluSTer. FCUL. Lisboa. 2006.

FUJITA, C. C.; ODEBRECHT, C. Short term variability of chlorophyll a and phytoplankton composition in a shallow area of the Patos Lagoon Estuary (Southern Brazil). Atlântica, v. 29, n.2, p. 93-106. 2007.

GALDINO, T. S. Zooplâncton Estuarino nas desembocaduras norte e sul do Canal de Santa Cruz, Itamaracá, PE. (Monografia de Bacharelado). Universidade Federal de Pernambuco. Recife, 2004.

GRASSHOFF, K. et al. Methods of seawater analysis. New York. Velag Chemie, 1983. Ed. 2, 317p.

GREGO, C. K. S.; FEITOSA, F. A. N.; HONORATO DA SILVA, M.; SILVA-CUNHA, M. G. G.; NASCIMENTO-FILHO. G. A. Fitoplâncton do ecossistema estuarino do rio Ariquindá (Tamandaré, PE, Brasil); Variáveis Ambientais, biomassa e produtividade primária. Atlântica, Rio Grande,. v.31, n.2, p 183-198. 2009.

GREGO, C. K da S. Distribuição espacial e sazonal da composição e biomassa

fitoplanctônica correlacionadas com a hidrologia do estuário do rio Timbó (Paulista, 
CASTRO, N. F.; FEITOSA, F. A. do N.; FLORES MONTES, M. de J. Avaliação das condições Ambientais do estuário do rio Carrapicho (Itamaracá- PE): Biomassa fitoplanctônica e Hidrologia.

Pernambuco). Dissertação (Mestrado em Oceanografia) Departamento de Oceanografia, Universidade Federal de Pernambuco. Recife, 2004. p.117.

HONORATO DA SILVA, M. Fitoplâncton do estuário do rio Formoso (rio Formoso, Pernambuco, Brasil): biomassa, taxonomia e ecologia. Dissertação (Mestrado em Oceanografia Biológica) Departamento de Oceanografia, Universidade Federal de Pernambuco, Recife, 2003. p.131.

LIRA, L. Geologia do Canal de Santa Cruz e praia submarina adjacente à ilha de Itamaracá-PE. Dissertação (Mestrado em Geociências). Inst. Geoc., UFRS. Porto Alegre, 1975. p.107.

LOSADA, A. P. M.; FEITOSA, F. A. N.; LINS, I. C. Variação sazonal e espacial da biomassa fitoplanctônica nos estuários dos rios Ilhetas e Mamucaba (Tamandaré - PE), relacionada com parâmetros hidrológicos. Trab. Oceanogr. Univ. Fed. PE. Recife, v.28, n.2, p.1-18. 2003.

MACÊDO, S. J.; COSTA, K. M. P. Estudos ecológicos da região de Itamaracá, Pernambuco - Brasil. Condições hidrológicas do Estuário do Rio Botafogo. Ciência e Cultura. São Paulo, v.30 n. 7, p.346-368. 1978.

MATEUS, M.; MATEUS, S.; BARETTA, J.W. Basic concepts of estuarine ecology. In: NEVES, R.; BARETTA, J. W.; MATEUS, M. (Ed.) Perspective on integrated coastal zone mannegement in South American. ISTPRESS, 2008. Lisboa, 2008. p.3-14.

Medeiros, A. M. S.; BARbOSA, J. E. L.; MEdeiros, P. R.; ROCHA, R. H.; SilVA, L. F. Braz. T. Biol. v.70, n.3, p.551-557. 2010

MELO-MAGALHÃES, E. M.; KOENING, M. L; NOQUEIRA, E. M. S. Variação sazonal e espacial de algas cianofíceas no Complexo Estuarino Lagunar Mundaú/Manguaba, AlagoasBrasil. Arquivos de Ciências do Mar, v.37, p.63-76. 2004.

PARSONS, T. R.; STRICKLAND, J. D. H. Discusson of spectrophometric determination of marine-plant pigments, with revised equations for ascertaining chlorophyll-a and carotenois. Journal Marine Research, v.21 p.105-156. 1963.

PASSAVANTE, J. Z. de O.; FEITOSA, F. A. N. Dinâmica da produtividade fitoplanctônica na zona costeira marinha. In: ESKINAZI-LEÇA, E.; NEWMANN-LEITÃO, S.; COSTA, M. F. (Ed.). Oceanografia: um cenário tropical. Recife: Edições Bagaço, 2004. p.425-440.

PASSAVANTE, J. Z. de O.; GOMES, N. A.; ESKINAZI-LEÇA, E. Variação da Clorofila a do Fitoplâcton na Plataforma Continental de Pernambuco. Trabalhos Oceanográficos da Universidade Federal de Pernambuco. Recife, v. 20. p. 145-156.1987/89.

PAULO, J. G.; FLORES-MONTES, M. J.; SANTOS-JÚNIOR, A. C.; BATISTA, T. N. F.; TRAVASSOS, R. K.; NASCIMENTO-FILHO, G. A.: FEITOSA, F. A. N.; GASPAR, F. T.; PITANGA, M. E. Allochtonous and autochtonous organic matter in a urban tropical estuarine área of northeastern Brazil. Jornal of coastal Reseaich. v.64, p. 1798-1801. 2011.

PEREIRA-FILHO, J.; RÖRIG, L. R.; SCHETTINI, C. A. F.; SOPPA, M. A.; SANTANA, B. L.; SANTOS, J. E. Spatial changes in the water quality of Itajaí-Açú Fluvial-Estuarine System, Santa Catarina, Brazil. Annals of the Brazilian Academy of Sciences, 2010. v.82, p.963-982.

PORTO-NETO, F. Variação nictemeral e sazonal do zooplâncton no Canal de Santa Cruz, Itamaracá - PE. Recife. Dissertação de Mestrado. Recife (PE): Universidade Federal de Pernambuco. 1998.

RICKLEFS, R. E. A Economia da Natureza. Rio de Janeiro: Guanabara Koogan. 2003.

RODRIGUES, E. I.; CUTRIM, M. V. Relações entre as variáveis físicas, químicas e fisiológicas de três áreas estuarinas do norte do Brasil - São José de Ribamar, Cedral e Cajapió, MA. Arquivos do mar, Fortaleza, v. 43, n.2, p. 45-54. 2010. 
SANTOS, T. G.; BEZERRA-JÚNIOR, J. L.; COSTA, K. M. P.; FEITOSA, F. A. N. Dinâmica da biomassa fitoplanctônica e variáveis ambientais em um estuário tropical (Bacia do Pina, Recife-PE). Rev. Bras. Enga. Pesca, v.4, n. 1, 2009.

SANTOS, T. G.; GALVÃO, L. M. S.; NEUMANN-LEITÃO, S.; CUNHA, A. G. Zooplâncton como indicador biológico da qualidade ambiental nos estuários dos rios Carrapicho e Botafogo, Itamaracá-PE. Rev. Bras. Enga. Pesca. v.4, n.1. 2009.

SANTOS, T. L.; PASSAVANTE, J. Z. de O.; KOENING, M. L.; MACEDO, S. J.; LINS, C. S. Fitoplâncton do estuário do rio Jaguaribe (Itamaracá, Pernambuco, Brasil): Produção e hidrologia. Revista de Biologia Aquática, Tropical. Natal, v.10, p.43-69, 2000.

SCHETTINI, C. A. F; MIRANDA, T. B. Circulation on and suspended particulate matter transport in a tidally dominated estuary: Caravelas estuary, Bahia, Brazil. Brazilian journal of oceanography, São Paulo. v.58, n.1, p. 1-11.2010.

SILVA, A.P. Dinâmica temporal das larvas de Brachyura no Canal de Santa Cruz,

Pernambuco (Brasil), ao longo de um ciclo lunar. (Dissertação de Mestrado). Universidade Federal de Pernambuco. Recife, 2002.

SIPAUBA-TAVARES, L. H. Limnologia dos sistemas de cultivos. In: W.C. Valentin (ed). Carcinicultura de Água Doce; Tecnologia para produção de camarões. IBAMA/FAPESP. Brasília, 2008. p.47-75.

SMITH, V. H. Using primary productivity as an index of coastal eutrophication: the units of measurement matter. Journal Plankton Research, New York, v. 29, n. 1, p. 1-6. 2007.

STRICKLAND, J. D. H.; PARSONS, T. R. A Practical handbook of seawater analysis. 2 ed. Bulletin Fisheries Research Board of Canada, Ottawa, v. 167, p. 207-211, 1972.

TORRES, F. T. P.; MACHADO, P. J. O. Introdução à Climatologia. São Paulo: Cengage Learning, $2011.256 \mathrm{p}$.

TUNDISI, J. G.; TUNDISI, T. M. Hidrologia. Oficina de Texto. São Paulo, 2008.631p.

TUNDISI, J. G.; TUNDISI, T. M. Produção orgânica em ecossistemas aquáticos. Ciência e Cultura. São Paulo, v.28, n.8, p.864-887. 1976.

TUNDISI, J. G. O plâncton estuarino. Contr. Avulsas Inst. Oceano. São Paulo, V. 19, p.122. 1970.

UNESCO. Determination of photosynthetic pigments in sea-water. Working Group 17 with meat from 4 to 6 June 1964. Paris: [s.n.], 1966. 69 p. (Monography on Oceanography Methodology, 1).

UNESCO. International Oceanographic Table. Wormly, v. 2, 1973. 141p.

WU, J. T.; CHOU, T. L. Silicate as the limiting nutrient for phytoplankton in a subtropical eutrophic estuary of Taiwan. Estuar. Coast. Shelf Sci. v.58 p.155-162.2003. 